\title{
Bifunctional Taqll restriction endonuclease: redefining the prototype DNA recognition site and establishing the Fidelity Index for partial cleaving
}

Agnieszka Żylicz-Stachula, Olga Żołnierkiewicz, Katarzyna Śliwińska, Joanna Jeżewska-Frąckowiak and Piotr M Skowron*

\begin{abstract}
Background: The Taqll enzyme is a member of the Thermus sp. enzyme family that we propounded previously within Type IIS restriction endonucleases, containing related thermophilic bifunctional endonucleasesmethyltransferases from various Thermus sp.: TaqII, Tth111II, TthHB27l, TspGWI, TspDTI and Tsol. These enzymes show significant nucleotide and amino acid sequence similarities, a rare phenomenon among restriction endonucleases, along with similarities in biochemical properties, molecular size, DNA recognition sequences and cleavage sites. They also feature some characteristics of Types I and III.

Results: Barker et al. reported the Type IIS/IIC restriction endonuclease TaqII as recognizing two distinct cognate site variants (5'-GACCGA-3' and 5'-CACCCA-3') while cleaving 11/9 nucleotides downstream. We used four independent methods, namely, shotgun cloning and sequencing, restriction pattern analysis, digestion of particular custom substrates and GeneScan analysis, to demonstrate that the recombinant enzyme recognizes only 5'GACCGA-3' sites and cleaves 11/9 nucleotides downstream. We did not observe any 5'-CACCCA-3' cleavage under a variety of conditions and site arrangements tested. We also characterized the enzyme biochemically and established new digestion conditions optimal for practical enzyme applications. Finally, we developed and propose a new version of the Fidelity Index - the Fidelity Index for Partial Cleavage (FI-PC).

Conclusions: The DNA recognition sequence of the bifunctional prototype Taqll endonuclease-methyltransferase from Thermus aquaticus has been redefined as recognizing only 5'-GACCGA-3' cognate sites. The reaction conditions ( $\mathrm{pH}$ and salt concentrations) were designed either to minimize $(\mathrm{pH}=8.0$ and $10 \mathrm{mM}$ ammonium sulphate) or to enhance star activity ( $\mathrm{pH}=6.0$ and no salt). Redefinition of the recognition site and reaction conditions makes this prototype endonuclease a useful tool for DNA manipulation; as yet, this enzyme has no practical applications. The extension of the Fidelity Index will be helpful for DNA manipulation with enzymes only partially cleaving DNA.
\end{abstract}

\section{Background}

Restriction endonucleases (REases) are indispensable as molecular scissors in the analysis, rearrangement, cloning and sequencing of DNA [1-3]. Restriction-modification (RM) systems have been classified into four major types on the basis of their genetic and polypeptide

\footnotetext{
* Correspondence: skowronp@chem.univ.gda.pl

Institute for Environmental and Human Health Protection, Department of Chemistry University of Gdańsk, Sobieskiego 18, 80-952 Gdańsk, Poland
}

organization, cofactor requirements, and their modes of recognition and cleavage: I, II, III, and IV [4]. Of the 3945 biochemically or genetically characterized restriction enzymes [5] currently known, 3834 Type II RM systems make up the largest biochemically characterized fraction [5]. Only 299 of this vast number, however, are enzymes with different and unique specificities; the remainder are isoschizomers, that is, enzymes with the same substrate specificity as the prototype but originating from different bacterial genera, species or strains [5].

\section{() Biomed Central}


Worth mentioning among these enzymes are the subtype IIS REases, which, in contrast to orthodox Type II REases, interact with the asymmetric sequence and typically cut DNA in a strictly fixed location beyond its recognition site to produce blunt or sticky ends with 3'or $5^{\prime}$-overhangs [6]. The known prototype subtype IIS specificities discovered to date comprise only a small fraction of the possible asymmetric recognition sequences with no associated specific REase. For this reason, it is highly likely that new prototypical REases will be discovered within this very subtype. Statistically, there are many potential symmetric and asymmetric recognition sites: 256 possible combinations of 4-bp sites, 1024 of 5-bp sites, 4096 of 6-bp sites, 16384 of 7bp sites and 65536 of 8-bp sites. Even with the current advent of whole genome sequencing aided by sophisticated software analysis of the potential restriction endonuclease genes present, accumulation of novel prototype specificities is slow. As REases still form the core of recombinant technologies, new findings of these enzymes in nature or the creation of artificial specificities in vitro [7-10] or the improvement of existing ones (such as this work) is of scientific and practical significance. The palette of everyday cloning tools is enlarged with every new prototype that becomes available. Particularly refined improvements and applications of subType IIS enzymes have been pioneered by Wacław Szybalski since the 1980s: these include universal restriction endonucleases, DNA cleavage at a pre-programmed site, gene amplification, gene fusion, unidirectional DNA trimming, methylated base location in DNA and gene mutagenesis using excision linkers [7-11]. The majority of known Type II REases have been isolated from mesophilic bacteria. Such enzymes are stable at temperatures below $45^{\circ} \mathrm{C}$ and are usually rapidly denatured at higher temperatures. The relatively few restriction endonucleases capable of withstanding higher temperatures therefore represent an extremely useful additional molecular tool [12-14]. For this reason the investigation of existing restriction endonucleases and the search for novel, thermally stable ones is entirely justified.

83 thermostable Type II REases with different specificities have been discovered in species of the genus Thermus [15], including 17 prototypes: TatI [16], TauI [16], TaqI [17], TaqII [18], TfiI [19], TseI [20,21], TspDTI [22], TspGWI [23], Tsp4CI [24], TspEI [25], Tsp45I [26], TspRI [27], TstI [28], TsuI, TssI, Tth111I [29] and Tth111II [30]. Obviously, then, Thermus bacteria are a rich source of unique REases. A subset of these enzymes, the unique thermostable Type IIS REases from the Thermus sp. family, is worth mentioning. We have already published the criteria for defining the Thermus sp. family of REases [22]. Examples of the family include TspGWI [14,22,23,31], TspDTI [22], Tth111II [30],
TthHB27I [15], TaqII [18] and TsoI [15], Arvydas Lubys, personal communication). The members of this group are bifunctional enzymes with REase and methyltransferase (MTase) activities within a single polypeptide (subtype IIC, which partially overlaps subtype IIS). All are stimulated by S-adenosyl methionine (AdoMet) or its structural analogues sinefungin (SIN) and S-adenosyl homocysteine (AdoHcy), but otherwise they behave like Type II enzymes [6]. These enzymes also exhibit some features of Types I and III, however.

The bifunctional TaqII enzyme is closely related to TspGWI, a prototype of the Thermus sp. enzyme family [31]. According to Barker et al. TaqII REase recognizes the 5'-GACCGA-3' and 5'-CACCCA-3' sites and cleaves $11 / 9$ nucleotides downstream [18]. The enzyme generates a certain partial fragmentation pattern corresponding to cleavage at the target site [18]. Under the conditions tested previously, no complete TaqII digestion was obtained, either by native (isolated from Thermus aquaticus YT) or by recombinant enzyme [18]. This was probably due to preferential site cleavage in various DNA substrates. The restriction activity of TaqII is neither inhibited nor stimulated by ATP. Interestingly, in contrast to the TspGWI enzyme, TaqII REase displays marked differences in its response to AdoMet, which effectively stimulates its restriction endonuclease activity [22]. AdoMet is required for effective DNA methylation. Barker et al. noted minor endonuclease activity in TaqII preparation. However, the separation of this putative activity from TaqII in the course of purification was impossible, as native TaqII is present in Thermus aquaticus YT in minute amounts [18]. Purification is therefore complicated and results in low final preparation yields. In addition, non-specific nucleases, co-purifying with native TaqII, make precise digestions difficult. Further complications in the enzyme analysis stem from the fact that, like other enzymes from the Thermus sp. family, TaqII does not cleave DNA to completion to give a stable partial digestion pattern. After having noticed serious discrepancies between the experimentally obtained TaqII DNA digestion pattern (in the reaction buffer proposed by Barker et al.) and that of the recognition sequence published by Barker et al. [18], we decided to explore TaqII reaction features in greater detail. This paper has three aims: (i) to re-evaluate TaqII recognition and cleavage sites; (ii) to optimize both star-minimum and star-maximum reaction conditions for converting this prototype endonuclease, so far unused in recombinant DNA technology, into a useful molecular tool; (iii) to introduce the Fidelity Index for partially cleaving REases (FI-PC) - a useful variant of the Fidelity Index [32].

In this paper, we show that recombinant TaqII REase is unable to cleave after 5'-CACCCA-3' sites. Thus, the 
prototype recognition sequence should be redefined as cleaving after 5'-GACCGA-3' sites only. We determined the conditions both for minimizing and for stimulating star activity; we also introduced the Fidelity Index for Partial Cleavage (FI-PC).

\section{Results and discussion}

Devising artificial substrates differentiating Taqll recognition site variants

As both the native TaqII enzyme and that cloned into Escherichia coli (E. coli) (manuscript in preparation) exhibited the same cleavage pattern, the recombinant enzyme was selected for further work. Set up to explain the observed discrepancy between published [18] and observed TaqII specificity (not shown) using plasmid DNA substrates, the initial experiments were inconclusive, even though the cleavage patterns strongly suggested that the recognition sequence of this prototype differed from the sequence originally reported in 1984 [18]. Thus a set of five artificial DNA substrates from 390 to $402 \mathrm{bp}$ in length was devised and obtained by PCR using a combination of mutagenic primers. The substrates contained selected canonical sites - variant 5'CACCCA-3', variant 5'-GACCGA-3' or both - to eliminate/explore the potential stimulatory effect of two recognition sequences, present in the cis configuration, on the activity of TaqII REase (Figure 1). As shown in Figure $2 \mathrm{~A}$, the expected $48 \mathrm{bp}$ and $340 \mathrm{bp}$ restriction fragments from the digestion of two alternative DNA substrates, PCR(GACCGA) (Figure 1A) and PCR (CACCCA) (Figure 1B), containing a single $(\rightarrow)$ canonical site (either 5'-GACCGA-3' or 5'-CACCCA-3' [18], were obtained only for the first variant. Moreover, and typically of the TaqII mode of action (as it belongs to the Thermus sp. family, where all enzymes partially cleave DNA), TaqII digestion of PCR(GACCGA) was not complete. These results show clearly that 5'GACCGA-3' site is efficiently cleaved, whereas the second 5'-CACCCA-3' canonical site, reported by Barker et al. [18], was not cleaved at all, as detected in a very sensitive assay using the Sybr Green staining procedure. It is interesting to note that in contrast to the homologous TspGWI enzyme, which recognizes a related recognition site and also cleaves at 11/9 nt away, TaqII REase is capable of single, isolated cognate site cleavage. The results were further confirmed by the incubation of PCR (CACCCA/CACCCA) 390 bp DNA substrate, containing two convergent 5'-CACCCA-3' sequences (Figure 1C). As expected, no digestion of the substrate was detected using Sybr Green staining (Figure 2B). The same results were invariably obtained under a variety of buffer conditions (not shown). The experiments with bacteriophage lambda DNA also addressed this issue, as multiple 5'-CACCCA-3' sequences are present there in all possible arrangements. Even so, no clone was found to have resulted from 5'-CACCCA-3' cleavage (Table 1).

\section{Optimization of reaction conditions for Taqll REase activity}

The PCR substrates made for the precise quantitative determination of the optimal reaction conditions (as defined by the minimum amount of the enzyme needed to obtain a stable DNA digestion pattern, regardless of any accompanying star activity). Since TaqII exhibits pronounced star activity, two variants of the reaction conditions were determined, resulting in (1) minimum star activity, while maintaining reasonable cleavage activity, and (2) maximum stimulation of star activity. The Fidelity Index could be calculated from a comparison of the TaqII digestion patterns obtained in the established reaction buffers (1) and (2), enabling the rational use of TaqII in recombinant DNA technology.

As a starting point, we used a previously published buffer composition [18]. Three buffering systems exhibiting the highest buffering capacity in the $\mathrm{pH}$ range tested were used for optimal $\mathrm{pH}$ determination: sodium acetate-acetic acid for $\mathrm{pH}$ from 5.0 to 5.5, HEPES-KOH for $\mathrm{pH}$ from 6.0 to 7.0, and Tris- $\mathrm{HCl}$ buffer for $\mathrm{pH}$ from 7.5-9.5. The $\mathrm{pH}$ of the reaction buffers was adjusted at $65^{\circ} \mathrm{C}$ after all the buffer components had been added. The cleavage reactions were performed under unsaturating conditions, where the enzyme was a limiting factor (0.625: 1 molar ratio of the enzyme to 5'-GACCGA-3' sites for $30 \mathrm{~min}$ ). No restriction activity was detected in the 5.0-5.5 range; activity increased to values close to optimal (from 41.6 to $82 \%$ ) in the 6.0-7.0 range, and reached a maximum in the 7.5-9.5 range at $\mathrm{pH} 7.5-8.0$, while decreasing to $70 \%$ at $\mathrm{pH} 8.5$, to $34 \%$ at $\mathrm{pH} 9.0$ and to $33 \%$ at $\mathrm{pH} 9.5$ (Figure $3 \mathrm{~A}$ ). At optimized $\mathrm{pH}$ (= 7.5 ), a buffer with variable concentrations of ammonium sulphate was used to determine optimal ionic strength. Ammonium sulphate was chosen, as we noticed the stabilizing effect of either $\mathrm{NH}_{4}{ }^{+}$or $\left(\mathrm{SO}_{4}\right)^{2-}$ or both on TaqII enzyme, which translated into a longer lifetime of the enzyme in the reaction mixture and stronger suppression of star activity, as compared to $\mathrm{NaCl}$ or $\mathrm{KCl}$ (not shown). The maximum activity in the 0-70 mM concentration range tested was obtained between 0 and $10 \mathrm{mM}$ (Figure 3B). As we did not observe any enzyme stabilization or activity increase with glycerol or nonionic detergents, we did not evaluate these parameters further.

\section{Determination of the Taqll star inhibitory/stimulatory condition and the Fidelity Indices}

Since TaqII exhibits substantial star activity, it is crucial for potential applications of the enzyme in recombinant DNA technology to find the conditions minimizing this 


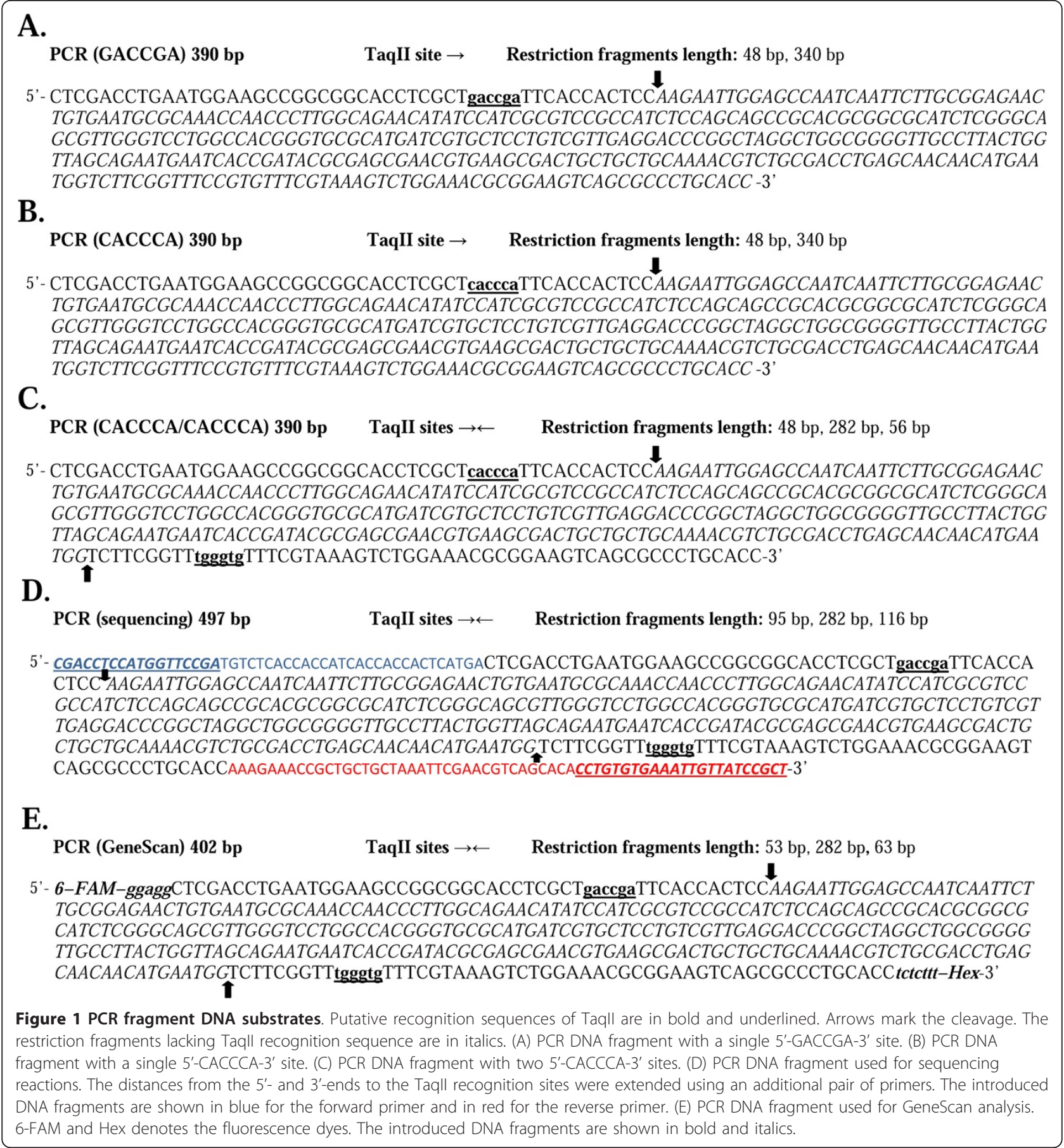

phenomenon. We had expected that the buffer conditions minimizing star activity might not necessarily match those of maximum activity, so we explored TaqII behaviour under enzyme oversaturating conditions to pinpoint subtle changes in star activity appearance; we also used a series of gel photographs, ranging from normal exposure to several stops of overexposure. The amount of enzyme activity used was effectively ca 400 times higher (assuming the confirmed overnight stability of TaqII, not shown) than that used for $\mathrm{pH}$ and ionic strength optima. In the $\mathrm{pH}$ range tested (5.0 to 9.5) star activity reached a maximum at $\mathrm{pH}=6.0$ and decreased sharply at $\mathrm{pH}=7.5$, which is also the value of general peak activity (Figure $4 \mathrm{~A}$ ). The results of the ionic strength effect are striking: there is nearly complete inhibition of star activity in 40-50 $\mathrm{mM}$ ammonium 


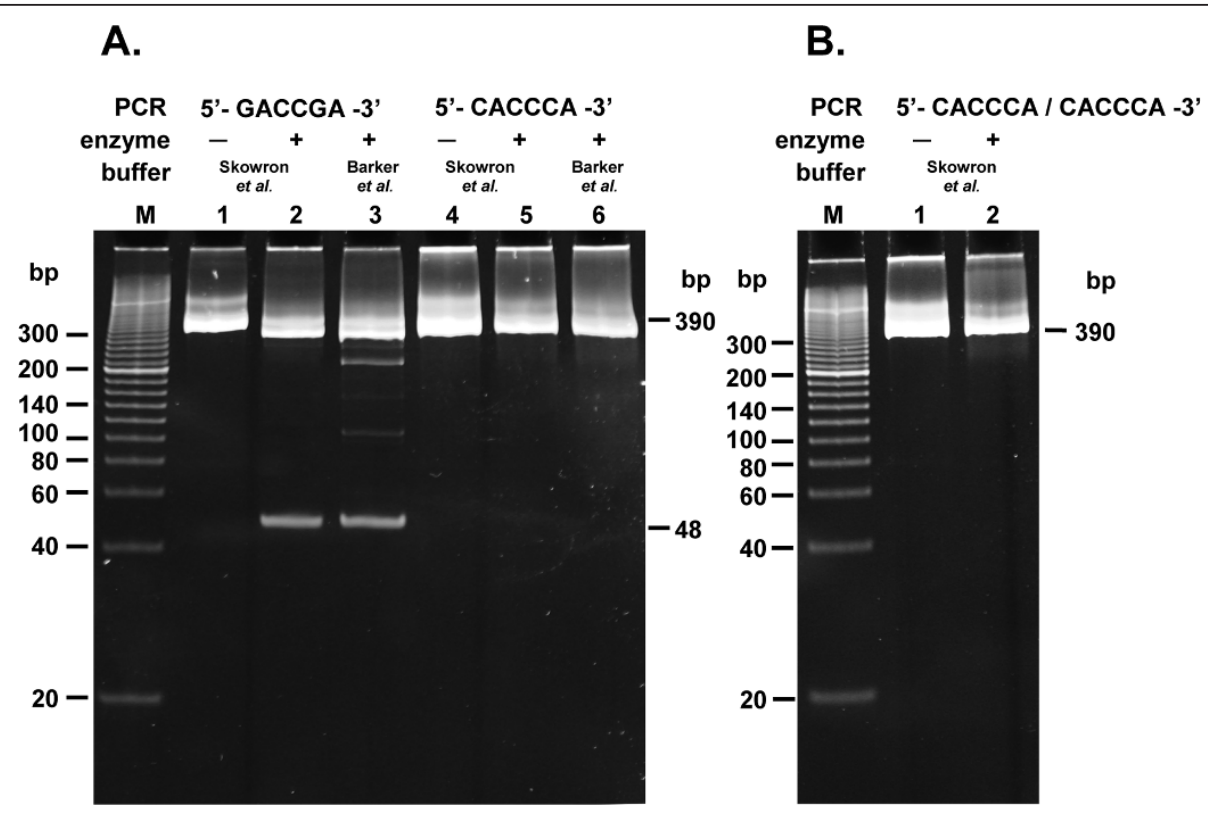

Figure 2 Taqll cleavage patterns of DNA substrates, containing $5^{\prime}$-CACCCA-3' and $5^{\prime}$-GACCGA-3' recognition sites. (A) Digestion of the PCR DNA fragment with a single $5^{\prime}$-GACCGA-3' or 5'-CACCCA-3' site. Digestion of $0.3 \mu \mathrm{g}(=1.2$-pmol recognition sites) PCR(GACCGA) substrate (lanes 1-3) and PCR(CACCCA) substrate (lanes 4-6) with 12 pmol Taqll, electrophoresed on a 15\% polyacrylamide/TBE gel. Lane M, Sigma PCR 20bp Low Ladder (selected bands marked); lane 1, undigested PCR(GACCGA) fragment; lane 2, digestion in the optimized buffer; lane 3, digestion in the buffer according to Barker et al. [18]; lane 4, undigested PCR(CACCCA) fragment; lane 5, digestion in the optimized buffer; lane 6, digestion in the buffer according to Barker et al. [18]. (B) Taqll digestion of the PCR DNA fragment with two convergent sites 5'-CACCCA-3'. Digestion of $0.3 \mu \mathrm{g}$ (= 2.4-pmol recognition sites) PCR(CACCCA/CACCCA) substrate with 24 pmol Taqll. Lane M, Sigma PCR 20-bp Low Ladder (selected bands marked); lane 1, undigested PCR fragment; lane 2, digestion in the optimized buffer.

sulphate, which is far from the optimal activity value of 0-10 mM (Figure 4B). Thus we determined the minimum star activity conditions ("clean" DNA digestion for cloning technology) at $\mathrm{pH} 8.0$ in $10 \mathrm{mM}$ ammonium sulphate, while maximum star activity was obtained at $\mathrm{pH} 6.0$ in $0 \mathrm{mM}$ ammonium sulphate (no salt).

These conditions were then used to carry out titration in order to determine and compare Fidelity Indices at both extremes. In order to apply the Fidelity Index [32] to TaqII, which gave a stable partial digestion pattern as the final reaction result, we needed to define a variant of the Fidelity Index for such REases. We established the Fidelity Index for Partial Cleavage (FI-PC) as the ratio of the maximum amount of enzyme showing no star activity to the minimum amount needed to obtain a stable partial digestion pattern. Figure 5A shows the titration under close to the originally reported conditions [18] of TaqII activity and under optimal (for nonstar) buffer conditions: $\mathrm{pH} 8.0$ and $10 \mathrm{mM}$ ammonium sulphate. There were no digestions with a 0.78: 1 molar ratio of the enzyme to cognate site 5'-GACCGA-3', but a stable partial digestion pattern was obtained at 3.12: 1 . TaqII is a bifunctional endonuclease-methyltransferase and it was observed to be a "slow" enzyme, just like other Thermus sp. family enzymes [14,22,23,31]. Nevertheless, when we extended the digestion time beyond the standard titration conditions presented in Figure 5A, substantial digestion was obtained at the molar ratio of

Table 1 Specificity of Taqll REase.

\begin{tabular}{lcc}
\hline Taqll recognition sequence variant & $\begin{array}{l}\text { Theoretical number of Taqll recognition } \\
\text { sequences in bacteriophage } \lambda \text { DNA }\end{array}$ & $\begin{array}{l}\text { Number of cleaved Taqll recognition sequences } \\
\text { (insert clones ends analysed) }\end{array}$ \\
\hline 5'-GACCGA-3' $^{\prime}$ & 10 & 39 \\
5'-CACCCA-3' & $?$ \\
Undetermined degenerate Taql** star &
\end{tabular}

Determination of the Taqll recognition sequence and cleavage positions by shotgun cloning and sequencing of the resulting clones.

Relaxed recognition sites were determined by shotgun cloning and sequencing of the Taqll restriction fragments obtained. After digestion, DNA was blunted with T4 DNA polymerase and cloned into the Smal site of the pUC19 vector. Taqll 5'-GACCGA-3' and Taqll 5'-CACCCA-3', canonical recognition sequences of the enzyme as described by Barker et al. [18]; Taqll*, variants of relaxed recognition sequences. 


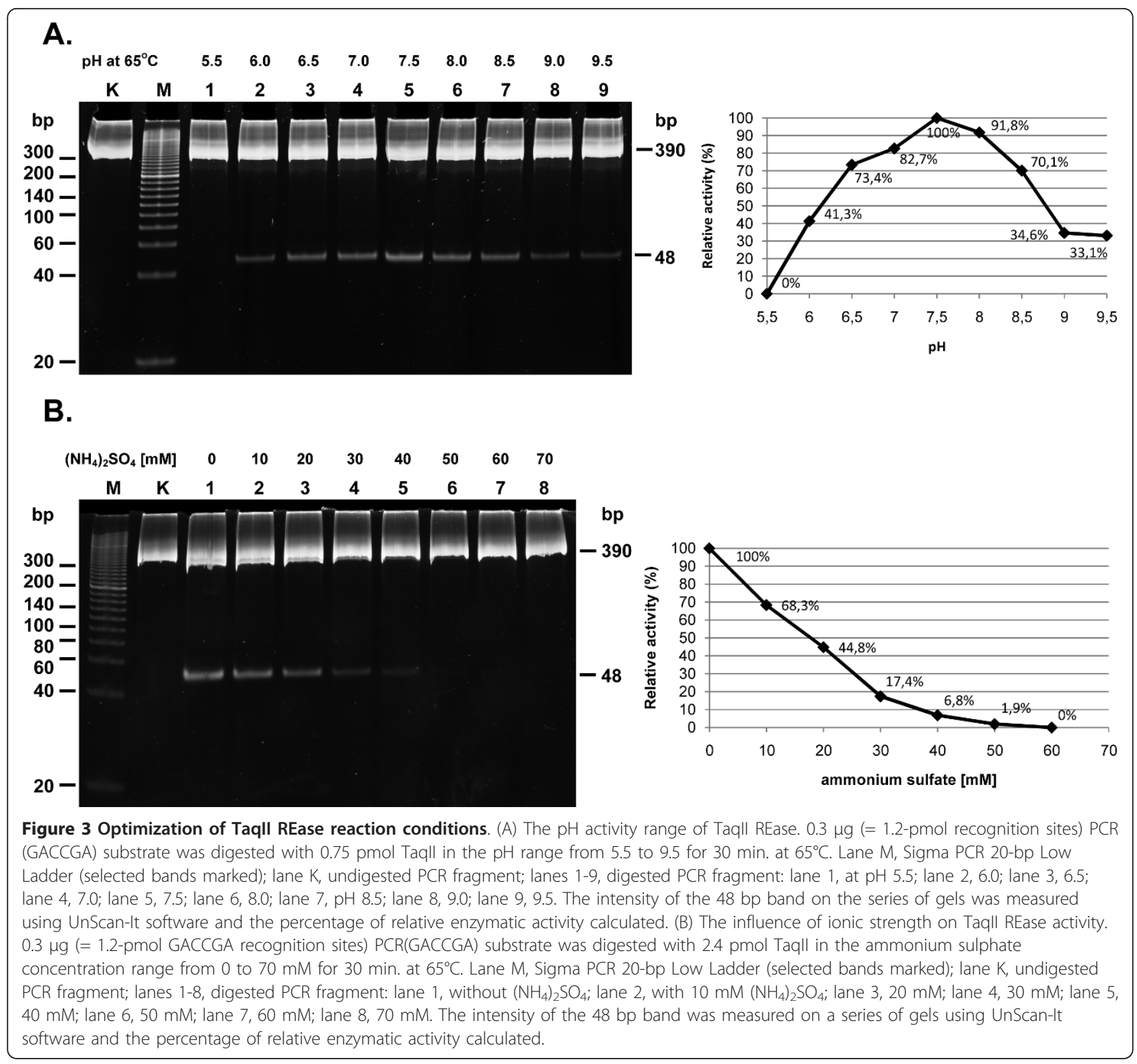

0.78: 1, indicating that TaqII is a multi-turnover enzyme (not shown). No star bands were detected until the ratio of 50: 1 was reached. The highest ratio tested (100: 1) evidently became inhibitory, though still leading to digestion and no star bands, possibly due to the formation of dominant non-specific REase-DNA complexes. Thus, FI-PC takes values of $>16-32$ for the optimized conditions, which is close to or exceeds the FI value originally established as the Enzyme Class "good" [32]. This finding is important for practical applications of TaqII in recombinant DNA methodology, with minimal star activity interfering with the desired cleavage pattern. On the other hand, as can be seen in Figure 5B, very strong star activity was detected, dominating the expected non-star bands, under maximally relaxing conditions ( $\mathrm{pH}$ 6.0, $0 \mathrm{mM}$ ammonium sulphate). Under these conditions, FI-PC fell to 2 only. These conditions are actually also useful in DNA manipulation methods when applied to frequent cutter techniques, such as representative library preparations, RFLP, precise mapping, anonymous primer generation [33] or Thermal Cycle Labelling [34]. We are developing the "TaqII star" technology further (manuscript in preparation).

\section{Determination of Taqll recognition sequence and cleavage site}

The most significant proof of the redefinition of the prototype TaqII specificity came from the digestion of custom 


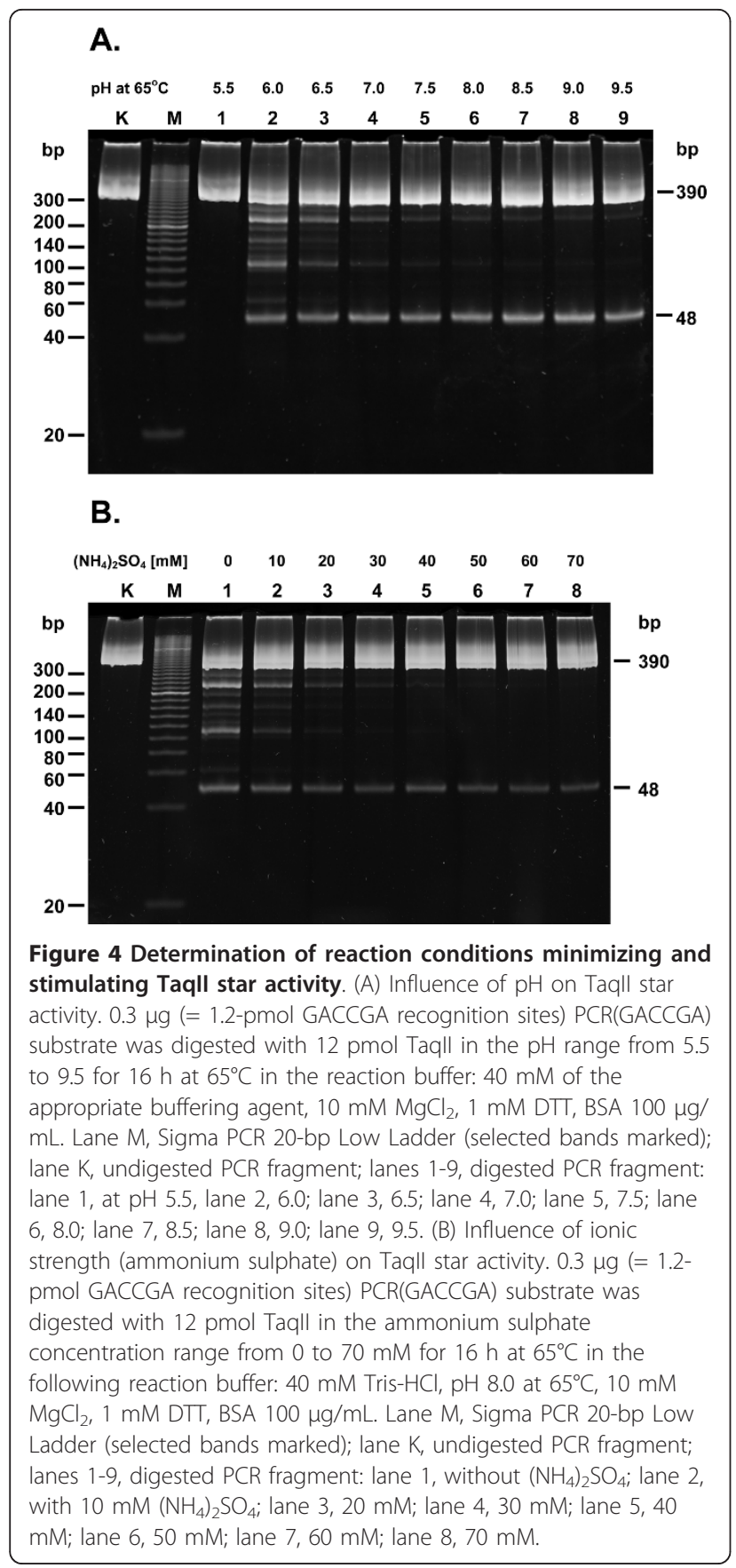

devised substrates (Figure 1, Figure 2), containing both variants of the originally reported recognition sequence [18]. Those results have been confirmed with three additional independent methods: shotgun cloning of bacteriophage lambda DNA cut with TaqII and end-repaired, direct DNA sequencing of TaqII digestion products, and GeneScan analysis of the gel isolated TaqII restriction fragment. Since a large number of 5'-GACCGA-3' sequences (10 sites) and 5'-CACCCA-3' sequences (18 sites) are present in the bacteriophage lambda genome,

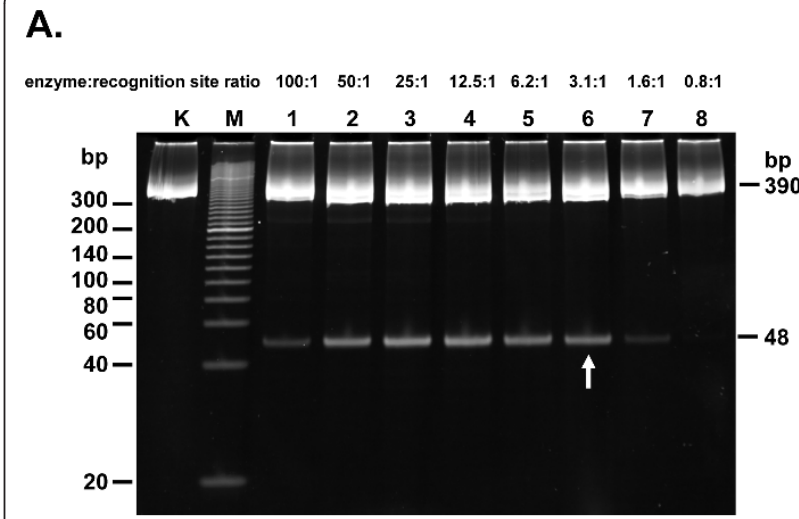

B.

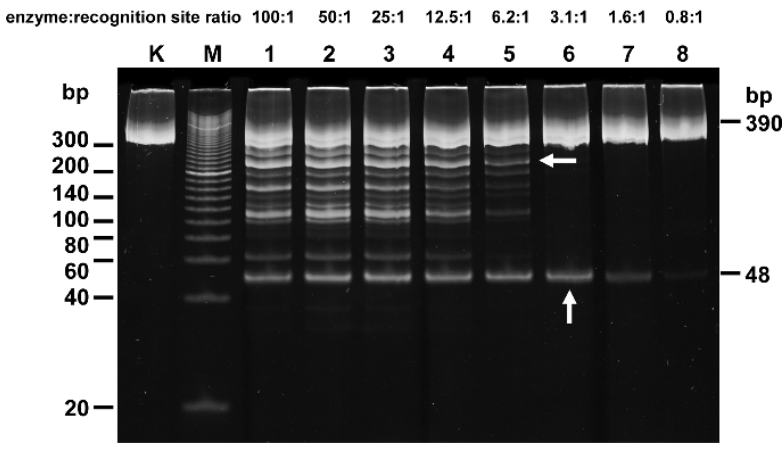

Figure 5 Extending the Fidelity Index to REases partially cleaving DNA: determination of minimum and maximum values for Taqll. (A) Taqll Fidelity Index under star inhibitory conditions. $0.3 \mu \mathrm{g}$ (= 1.2-pmol GACCGA recognition sites) PCR (GACCGA) substrate was digested with decreasing amounts of Taqll for $1 \mathrm{~h}$ at $65^{\circ} \mathrm{C}$ in the following buffer: $40 \mathrm{mM}$ Tris- $\mathrm{HCl}, \mathrm{pH}$ 8.0, at $65^{\circ} \mathrm{C}, 10 \mathrm{mM}\left(\mathrm{NH}_{4}\right)_{2} \mathrm{SO}_{4}, 10 \mathrm{mM} \mathrm{MgCl} 2,1 \mathrm{mM}$ DTT, BSA $100 \mu \mathrm{g} / \mathrm{mL}$. The final glycerol concentration was 5\%. Lane K, undigested PCR fragment; lane M, Sigma PCR 20-bp Low Ladder (selected bands marked); lanes 1-8, digested PCR fragment: lane 1: with 120 pmol Taqll; lane 2, 60 pmol; lane 3, 30 pmol; lane 4, 15 pmol; lane 5, 7.5 pmol; lane 6, 3.75 pmol; lane 7, with 1.87 pmol; lane 8, 0.94 pmol. (B) Taqll Fidelity Index under star stimulated conditions. $0.3 \mu \mathrm{g}$ (= 1.2-pmol GACCGA recognition sites) PCR(GACCGA) substrate was digested with decreasing amounts of Taqll for $1 \mathrm{~h}$ at $65^{\circ} \mathrm{C}$ in the following buffer: $40 \mathrm{mM}$ Tris- $\mathrm{HCl}, \mathrm{pH} 6.0$, at $65^{\circ} \mathrm{C}, 10 \mathrm{mM} \mathrm{MgCl}, 1$ $\mathrm{mM}$ DTT, BSA $100 \mu \mathrm{g} / \mathrm{mL}$. The final glycerol concentration was $5 \%$. Lane K, undigested PCR fragment; lane M, Sigma PCR 20-bp Low Ladder (selected bands marked); lanes 1-8, digested PCR fragment: lane 1: with $120 \mathrm{pmol}$ Taqll; lane 2, 60 pmol; lane 3, 30 pmol; lane 4, 15 pmol; lane 5, 7.5 pmol; lane 6, 3.75 pmol; lane 7, 1.87 pmol; lane 8, 0.94 pmol.

this approach eliminates any bias towards potentially unfavourable nearest neighbourhood locations of the recognition sites and also the rather remote possibility of double divergent or convergent 5'-CACCCA-3' sequence arrangements being needed for cleavage, since all possible combinations of both sequence arrangements are present in lambda DNA. Even so, no cleavage is observed after 5'CACCCA-3' sites. 
For the shotgun cloning approach, the original Barker et al. [18] reaction buffer was used for a direct comparison of the results. Even though there is an excess of 5'CACCCA-3' sequences over 5'-GACCGA-3' sequences in bacteriophage lambda DNA, 39 of the 98 insert ends in the clones analysed were DNA fragments resulting from 5'-GACCGA-3' site cleavage and none from 5'CACCCA-3' sequence cleavage. Interestingly, in addition to the expected insert ends obtained, 59 ends are apparently due to star activity at 5'-GACCGA-3' sequences (Table 1), where no simple relaxation pattern is observed, as in the case of our previous report concerning related TspGWI [14]. This indicates that star activity, traditionally treated as an unwanted artifact, is in fact, for certain enzymes, a naturally inherent enzymatic activity (further work in progress). Even though the star minimizing buffer composition is much closer to physiological conditions in vivo than the star promoting condition, a strikingly high content of star cleaved insert ends is observed in the clones.

Direct confirmation of the previous findings came from the run-off sequencing approach. The PCR(sequencing) 497 bp DNA substrate (Figure 1D), containing convergent 5'-CACCCA-3' and 5'-GACCGA-3' sequences located on the same DNA fragment, was cleaved with TaqII REase and subjected to DNA sequencing with the dideoxy chain termination method utilizing fluorescent labelling in the $\alpha$ position. The PCR substrate generated was devised to serve as an internal control for TaqII cleavage and DNA sequencing - both cognate site variants were present in the same DNA molecule. The investigated sequences are clearly seen because of the distance of 11/9 nt between the cleavage site and the DNA recognition sequence (Figure 6AB). Unfortunately, owing to the known features of thermostable DNA polymerase already included in the pre-mixed sequencing kit routinely used by the commercial service that we employed, resulting in polymerization difficulties at the very end of a linear DNA template that are additionally complicated by the addition of adenines at the 3' end of the synthesized DNA, the precise cleavage point could not be reliably confirmed by the direct sequencing approach. Nevertheless, sequencing enabled the "clean" sequence to be read through the recognition sequence variant 5'GACCGA-3', followed by DNA cleavage in the region of $11 / 9$ nt downstream. On the other hand, the sequencing reaction goes through the putative cleavage region located 11/9 downstream from the recognition sequence variant 5'-CACCCA-3' without any decrease in signal strength (Figure 6B). These results clearly confirmed that TaqII neither recognizes nor cleaves the 5'-CACCCA-3' DNA sequence variant.

In order to establish the recognition site with an independent technique and to obtain final confirmation of the recognition of the variant 5'-GACCGA-3' as well as cleavage at $11 \mathrm{nt}$ downstream in the top strand we used commercial GeneScan technology. Based on the capillary electrophoresis of a set of labelled standards of fixed length with 1-bp resolution, this method provides a simple and precise means of comparing the length of the TaqII cleavage products when electrophoresed together. This approach eliminates the above difficulties associated with the sequencing approach, where DNA polymerase does not yield a clean end sequence. For this purpose a TaqII substrate was prepared: this is a PCR fragment of $402 \mathrm{bp}$, containing both 5'-GACCGA3' and 5'-CACCCA-3' sites, located at opposite ends of the DNA molecule (Figure 1E). The cleavage of the DNA substrate should result in the $53 \mathrm{bp}, 282 \mathrm{bp}$ and $63 \mathrm{bp}$ restriction fragments (Figure 1E) if completely digested at both sequences. However, no complete TaqII digestion of the $402 \mathrm{bp}$ PCR was obtained under the variety of conditions tested. A larger gel-isolated partial digestion fragment, the length of which is in the optimal range for GeneScan reading, was analysed. The value of $347 \mathrm{nt}(+/-1 \mathrm{nt}$ as error range reported by the GeneScan service provider) thus obtained is in perfect agreement with 11/9 cleavage after the 5'-GACCGA-3' site variant.

The four approaches presented in this paper clearly show that TaqII cleaves only after 5'-GACCGA-3' sequences. This fundamental difference, as compared to the originally published prototype [18], may be due to a number of factors: $(i)$ in 1984 DNA analysis technology was much less refined than nowadays, so the 5'CACCCA-3' variant would have been an artifact of the technique; (ii) since TaqII's star activity is strong, some of the star sites could have been mistakenly assigned as 5'-CACCCA-3'; (iii) native TaqII is present in minute amounts in the Thermus aquaticus YT strain, along with substantial non-specific nuclease activity; (iv) copurifying the third REase activity (5'-CACCCA-3'), in spite of the application of several chromatographic steps. Thus, taken together, crude and low concentration preparation could have led to false cognate site determination. Redefining the prototype specificity along with the quantitative Fidelity Index data and establishing compromise digestion conditions, where some of the enzyme's activity is sacrificed in exchange for "clean" cleavage with minimum star activity, provides a new, useful molecular cloning tool - a robust thermostable REase with unique specificity.

\section{Conclusions}

$i$. The recognition DNA sequence of TaqII recombinant restriction endonuclease has been redefined as 5'-GACCGA-3' only.

$i$ i The cleavage site distance has been confirmed. 


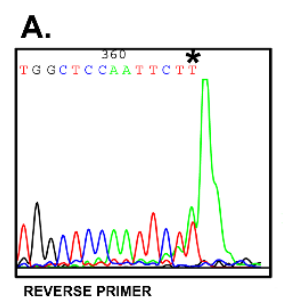

C.

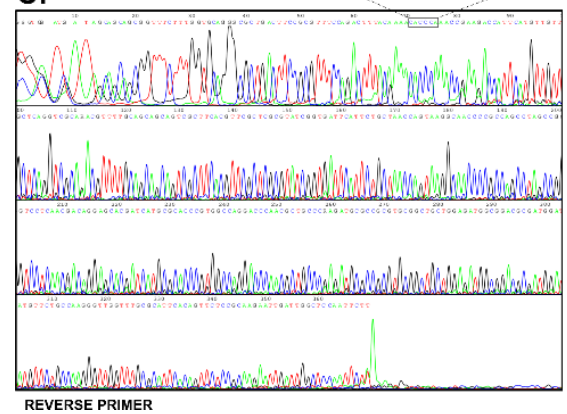

B.

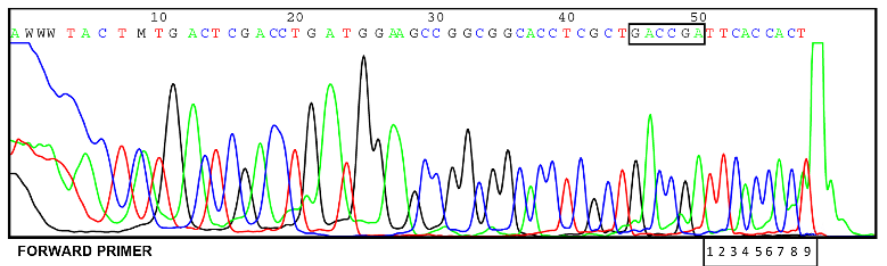

D.

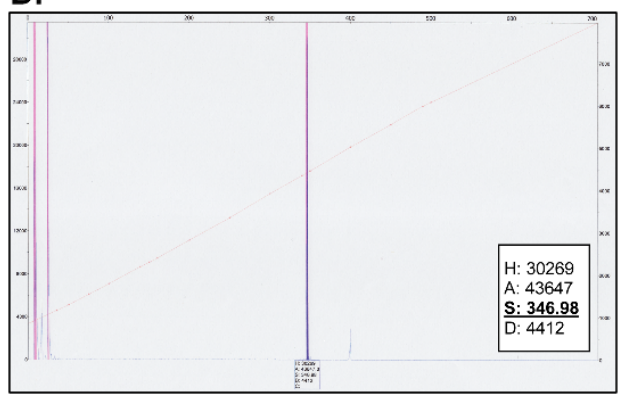

Figure 6 Determination of Taqll REase recognition sequence and cleavage site. Cleavage reactions of PCR(sequencing) and PCR(GeneScan) DNA substrates were performed as described in Materials and Methods. (A) This panel is the enlargement of the sequence end shown in Figure 6C. DNA sequencing of a $401 \mathrm{bp}$ Taqll cleavage reaction product using reverse primer, annealing to the top strand, as arbitrarily set for the strand containing 5'-GACCGA-3' cleavable Taqll site (Figure 1D). The appropriate DNA fragment was isolated from an agarose gel following gel electrophoresis. The asterisk denotes the cleavage point at position 98 of the substrate DNA fragment (Figure 1D). (B) DNA sequencing of a 95 bp Taqll cleavage reaction product using forward primer, annealing to the bottom strand, as arbitrarily set for the strand containing 5'-GACCGA$3^{\prime}$ cleavable Taqll site (Figure 1D). Thus the polymerization reaction goes through 5'-GACCGA-3' and stops at the end of the bottom strand template due to the cleavage distance of $9 \mathrm{nt}$. The appropriate DNA fragment was isolated from an agarose gel following gel electrophoresis. (C) DNA sequencing of non-purified Taqll cleavage reaction products using reverse primer, annealing to the top strand, as arbitrarily set for the strand containing 5'-GACCGA-3' cleavable Taqll site (Figure 1D). The sequencing reaction ends at the Taqll cleavage point at the 98 position of the substrate PCR(sequencing) DNA fragment (Figure 1D). (D) GeneScan gel analysis of Taqll cleavage. Taqul-cleaved 5'-labelled 402 bp PCR was gel purified and capillary electrophoreses in the presence of labelled DNA length markers. The Taqll cleavage product length reading of $347 \mathrm{nt}$ (assuming standard +/- $1 \mathrm{nt}$ error of the GeneScan) indicates 11/9 cleavage points after the 5'-GACCGA-3' site.

iii. The $\mathrm{pH}$ and salts (ammonium sulphate) optima were determined.

$i v$. The reaction conditions for inhibiting and stimulating the strong star activity of TaqII were established.

$v$. The redefinition of the TaqII recognition sequence together with the reduction/elimination of its star activity adds this enzyme to the palette of useful DNA cleavage specificities.

$v i$. The previously defined Fidelity Index [32] has been extended to REases, thus yielding a stable partial digestion pattern.

\section{Methods}

\section{Bacterial strains, media and reagents}

The taqIIRM gene was cloned in several configurations and used to produce the TaqII recombinant protein (manuscript in preparation). Escherichia coli BL21DE3 $\left\{\mathrm{F}^{-}\right.$omp $T h s d S_{B}\left(r_{B}{ }^{-} m_{B}{ }^{-}\right)$gal dcm (DE3)\} (Novagen) was used for taqIIRM gene expression. Escherichia coli DH11S \{mcrA $\Delta\left[\right.$ mrrhsdRMS $\left(\mathrm{rK}^{-}, \mathrm{mK}^{+}\right)$-mcrBC] $\Delta($ lacproAB) $\Delta($ recA1398) deoR, rpsL, srl-thi, supE/F proAB+
lacIQZAM15\} (Life Technologies, Gaithersburg, MD, USA) was used for the transformation of ligation mixtures and DNA propagation.

The Plasmid Mini, Gel-Out and Clean-Up DNA purification kits were from A\&A Biotechnology (Gdańsk, Poland); SmaI restriction endonuclease and T4 DNA polymerase from Eurx Molecular Biology Products (Gdańsk, Poland); the PCR 20-bp Low Ladder from Sigma-Aldrich Poland; Taq DNA Polymerase, $\lambda$ DNA and plasmids pBR322 and pUC19 from Vivantis Technologies (Shah Alam, Malaysia). The DNA sequencing, GeneScan and PCR primer synthesis were performed at Genomed (Warsaw, Poland). All other reagents were purchased from Sigma-Aldrich (St. Louis, MO, USA).

\section{Taqll activity unit definition}

Since TaqII does not yield complete digestion, regardless of the amount of the enzyme used, one unit of TaqII enzymatic activity is defined as the minimum amount of the enzyme needed to yield a stable digestion pattern during $1 \mathrm{~h}$ at optimum temperature in optimum buffer, using $1 \mu \mathrm{g}$ of pUC19 plasmid DNA. 


\section{PCR fragment DNA cleavage assay}

The TaqII recognition sites were created using a pair of primers introducing specific point mutations (the changed nucleotides are written in small letters) within the PCR fragment amplified from pBR322 plasmid DNA. Two alternative PCR fragments (390 bp): PCR (GACCGA) and PCR(CACCCA) containing single $(\rightarrow)$ originally published canonical sites for TaqII [18], either 5'-GACCGA-3' or 5'-CACCCA-3', were amplified using Taq DNA polymerase and a pair of primers: RTaqII 5'GGTGCAGGGCGCTGACTTCC-3' and 1FTaqII 5'TCGACCTGAATGGAAGCCGGCGGCACCTCGCT gACcGATTCACCACT-3' or 2FTaqII 5'-TCGACCT GAATGGAAGCCGGCGGCACCTCGCTcACccATT CACCACT-3', respectively. The cleavage pattern of the DNA substrates used, expected from published data [18], should result in the $48 \mathrm{bp}$ and $340 \mathrm{bp}$ restriction fragments (Figure 1AB). For the PCR(CACCCA/ CACCCA) substrate, an additional 5'-CACCCA-3' site was introduced to the PCR(CACCCA) to generate a substrate containing two TaqII divergent recognition sites using reverse primer 2RTaqII 5'-GGTGCAGG GCGCTGACTTCCGCGTTTCCAGACTTTACGAAA CAccCAAACCGAAGA-3' (Figure 1C). TaqII cleavage of PCR fragments was carried out in the appropriate reaction buffer at $65^{\circ} \mathrm{C}$. The TaqII cleavage reaction of the PCR DNA fragment was performed in the following buffers: $10 \mathrm{mM}$ Tris- $\mathrm{HCl}, \mathrm{pH} 7.5$, at $65^{\circ} \mathrm{C}, 10 \mathrm{mM}$ $\mathrm{MgCl}_{2}, 1 \mathrm{mM}$ DTT, BSA $100 \mu \mathrm{g} / \mathrm{mL}$ and in the reaction buffer proposed by Barker et al:: $6 \mathrm{mM}$ Tris- $\mathrm{HCl}, \mathrm{pH}$ 7.5, $6 \mathrm{mM} \mathrm{MgCl} 2,6 \mathrm{mM} \beta$-mercaptoethanol and 100 $\mu \mathrm{g} / \mathrm{ml}$ gelatin [18]. The protein to DNA recognition site molar ratio differs depending on the experiment. The reaction volume was $50 \mu \mathrm{L}$. After $16 \mathrm{~h}$, the reactions were quenched with phenol/chloroform, and DNA was ethanol-precipitated from the aqueous phase. The DNA precipitate was collected by centrifugation and dissolved in $10 \mathrm{mM}$ Tris- $\mathrm{HCl}, \mathrm{pH} 8.0$, at $25^{\circ} \mathrm{C}$. The products were analysed by electrophoresis in either $2 \%$ agarose or $15 \%$ polyacrylamide gels.

\section{$\lambda$ DNA cleavage assay}

Cleavage was carried out in the reaction buffer proposed by Barker et al. [18]. The reaction volume of $50 \mu \mathrm{L}$ contained 0.3 pmol recognition sites 5'-GACCGA-3' and 3 pmol recombinant TaqII protein. The molar ratio of protein to DNA 5'-GACCGA-3' recognition sites was approximately 10:1, and that of protein to DNA 5'-GACCGA-3' and 5'CACCCA-3' recognition sites was approximately 0.36:1. After $16 \mathrm{~h}$, the digestion was quenched with phenol/chloroform, and DNA was ethanol-precipitated from the aqueous phase. The DNA precipitate was collected by centrifugation and dissolved in $10 \mathrm{mM}$ Tris $-\mathrm{HCl}, \mathrm{pH} 8.0$, at $25^{\circ} \mathrm{C}$. To determine the recognition sequence and cleavage sites, the
DNA samples were treated with T4 DNA polymerase in the presence of dNTP and subjected to shotgun cloning. All concentrations of TaqII given here refer to the monomeric form of protein Mr 118, 500.

\section{Optimization of Taqll REase reaction conditions}

The investigations into the influence of $\mathrm{pH}$ on recombinant TaqII/TaqII* REase activity were carried out for the range from 5.0 to 9.5. The $\mathrm{pH}$ of all the reaction buffers was determined at the reaction temperature $\left(65^{\circ}\right.$ C). The following $40 \mathrm{mM}$ biological buffers were used: sodium acetate buffer for $\mathrm{pH}$ from 5.0 to 5.5, HEPES buffer for $\mathrm{pH}$ from 6.0 to 7.0, and Tris- $\mathrm{HCl}$ buffer for $\mathrm{pH}$ from 7.5-9.5.

The TaqII cleavage reactions of the PCR (GACCGA) DNA substrate were performed at $65^{\circ} \mathrm{C}$ in the reaction buffers: $40 \mathrm{mM}$ of the appropriate buffering agent, 10 $\mathrm{mM} \mathrm{MgCl} 2,1 \mathrm{mM}$ DTT, BSA $100 \mu \mathrm{g} / \mathrm{mL}$. All the reaction mixtures contained $1.2 \mathrm{pmol}$ recognition site and 0.75 pmol recombinant TaqII protein. The molar ratio of protein to DNA recognition sites was approximately $0.625: 1$. The reaction volume was $50 \mu \mathrm{L}$. After $30 \mathrm{~min}$, the reactions were quenched with phenol/chloroform, and DNA was ethanol-precipitated from the aqueous phase. The DNA precipitate was collected by centrifugation and dissolved in $10 \mathrm{mM}$ Tris- $\mathrm{HCl}, \mathrm{pH} 8.0$, at $25^{\circ} \mathrm{C}$. The products were analysed by electrophoresis in either $2 \%$ agarose or $15 \%$ polyacrylamide gels.

The intensity of the band corresponding to the $48 \mathrm{bp}$ TaqII restriction fragment was measured using UnScanIt software and the relative enzymatic activity was calculated as a percentage. The optimal reaction buffer was chosen and the influence of the increasing ionic strength on the reduction of TaqII* star activity was determined. Ammonium sulphate in the concentration range from 0 to $70 \mathrm{mM}$ was added to the reaction buffer in order to obtain maximum TaqII activity with simultaneous elimination of TaqII* activity.

Determination of Taqll cleavage site by DNA sequencing For the PCR(sequencing) substrate, an additional 5'CACCCA-3' site was introduced to the PCR(GACCGA) DNA fragment using the analogous reverse primer 2RTaqII 5'-GGTGCAGGGCGCTGACTTCCGCGT TTCCAGACTTTACGAAACAccCAAACCGAAGA-3' (Figure 1D). The distances from the 5 '- and 3'-ends to the TaqII recognition sites were extended using a pair of primers, complementary to the PCR (GACCGA/CACCCA) substrate, in the second round of the PCR reaction. The DNA sequences of the primers used were: F63-390 5'CGACCTCCATGGTTCCGATGTCTCACCACCAT CACCACCACTCATGACTCGACCTGAATGGAA-3' and R75-390 5'-AGCGGATAACAATT TCACACAGGTGTGCTGACGTTCGAATTTAGCAG 
CAGCGGTTTCTTTGGTGCAGGGCGCTGA-3'. The resulting PCR fragment was $497 \mathrm{bp}$ in length (Figure 1D).

The TaqII cleavage of the PCR (sequencing) DNA substrate obtained was carried out in the appropriate reaction buffer at $65^{\circ} \mathrm{C}$. The TaqII cleavage reaction was performed in the reaction buffer proposed by Barker et al.: $6 \mathrm{mM}$ Tris- $\mathrm{HCl}, \mathrm{pH} 7.5,6 \mathrm{mM} \mathrm{MgCl}_{2}, 6 \mathrm{mM} \beta$ mercaptoethanol and $100 \mu \mathrm{g} / \mathrm{ml}$ gelatin [18]. The reaction mixture contained 56 pmol GACCGA recognition sites and $112 \mathrm{pmol}$ recombinant TaqII protein. The protein to DNA recognition site molar ratio was approximately 2:1. The reaction volume was $500 \mu \mathrm{L}$. After $3 \mathrm{~h}$, the reactions were quenched with phenol/chloroform, and DNA was ethanol-precipitated from the aqueous phase. The DNA precipitate was collected by centrifugation and dissolved in $10 \mathrm{mM}$ Tris- $\mathrm{HCl}, \mathrm{pH} 8.0$, at $25^{\circ} \mathrm{C}$. The products were analysed by electrophoresis in either $2 \%$ agarose or $15 \%$ polyacrylamide gels and subjected to DNA sequencing on a 3730xl DNA Analyser using the oligonucleotides F18seq-390: 5'-CGACCTCCATGG TTCCGA- 3' and R22seq-390: 5'-AGCGGATAACAA TTTCACACAGG-3' and BigDye ${ }^{\circledR}$ Terminator v3.1 Applied Biosystems (Life Technologies).

\section{Determination of Taqll recognition site by shotgun cloning}

The TaqII recognition site and cleavage positions were established by shotgun cloning and sequencing of the digestion products of bacteriophage $\lambda$ DNA. The TaqIIgenerated restriction fragment ends were blunted with $\mathrm{T} 4$ DNA polymerase in the presence of dNTPs, cloned into the SmaI site of pUC19 vector, transformed into E. coli DH11S, and plated onto X-gal/IPTG plates [35]. Plasmid DNA from 50 different bacterial clones (from white colonies) was isolated, and the fragment/vector junctions were sequenced. The sequence data obtained were then analysed using ABI Chromas 1.45 software (Perkin Elmer Applied Biosystems, Monza, Italy) and DNASIS 2.5 software (Hitachi Software, San Bruno, CA, USA).

\section{GeneScan analysis}

For the PCR(GeneScan) substrate, an additional 5'CACCCA-3' site was introduced to the PCR(GACCGA) DNA fragment (see Materials and Methods, Determination of TaqII cleavage site by DNA sequencing). In the second round of the PCR reaction, the fluorescence dyes 6-FAM and Hex were added to the 5'- and 3'-ends of DNA fragment using a pair of primers, complementary to the PCR (GACCGA/CACCCA) substrate. The DNA sequences of the primers used were F6FAM-390: 5'ggaggCTCGACCTGAATGGAA-3' and RHex-390 5'aaagagaGGTGCAGGGCG-3'. The PCR (GeneScan) fragment obtained was 402 bp in length (Figure 1E).
The cleavage reaction mixture $(500 \mu \mathrm{l})$ containing 6 $\mathrm{mM}$ Tris- $\mathrm{HCl}, \mathrm{pH} 7.5$ at $65^{\circ} \mathrm{C}, 6 \mathrm{mM} \mathrm{MgCl}_{2}, 6 \mathrm{mM} \beta$ mercaptoethanol and $100 \mu \mathrm{g} / \mathrm{ml}$ gelatin $38 \mathrm{pM}$ PCR (GeneScan) DNA substrate and $380 \mathrm{pM}$ of TaqII protein were incubated at $65^{\circ} \mathrm{C}$ for 16 hours. The products were analysed by electrophoresis in either $2 \%$ agarose or $15 \%$ polyacrylamide gels. The 345 bp restriction fragment was isolated from agarose and subjected to GeneScan analysis using an ABI 3730xl DNA Analyzer and internal size standard: GeneScan ROX-500 (PE Applied Biosystems). The data obtained were analysed using PeakScanner v 1.0 software (Applied Biosystems).

\section{Polyacrylamide gel electrophoresis}

Polyacrylamide gels (15\%) were prepared in $1 \times$ TrisBorate-EDTA (TBE) buffer [35]. The gels were visualized after staining with Sybr Green I using a 312-nm UV transilluminator and photographed with a SYBR Green gel stain photographic filter.

\section{Acknowledgements}

The authors would like to express their gratitude to Katarzyna Maczyszyn for the digital picture imaging and her valuable technical assistance. This work was supported by the Polish Ministry of Science and Higher Education under Grants No. NR12-0070-06/2009 and by DS/8452-4-0135-1 (OŻ), DS/ 8170-4-0170-10 (PMS), DS/8221 40140 1(AŻS) Gdansk University, Chemistry Department fund.

\section{Authors' contributions}

AŻS conceived the project, coordinated its execution, participated in the design and interpretation of the experimental analyses, performed some of the experiments and drafted the manuscript. OŻ performed most of the experiments. KŚ purified Taqll REase. JJF performed some of the experiments and participated in the preparation of the figures. PMS was the author of the concept of the Thermus sp. enzyme family and FI-PC, participated in the design and interpretation of the experiments, coordinated the execution of the project and drafted the manuscript. All the authors read and approved the final manuscript.

Received: 5 September 2011 Accepted: 5 December 2011

Published: 5 December 2011

\section{References}

1. Pingoud AJ, Alves J, Geiger R: Restriction enzymes. Methods Mol Biol 1993, 16:107-200.

2. Engler C, Gruetzner R, Kandzia R, Marillonet S: Golden Gate Shuffling: A one-pot DNA shuffling method based on Type IIS restriction enzymes. PLoS One 2009, 4(5):e5553.

3. Lippow SM, Aha PM, Parker MH, Blake WJ, Baynes BM, Lipovsek D: Creation of a type IIS endonuclease with a long recognition sequence. Nucleic Acids Res 2009, 37:3061-3073.

4. Roberts RJ, Belfort M, Bestor T, Bhagwat AS, Bickle TA, et al: A nomenclature for restriction enzymes, DNA methyltransferases, homing endonucleases and their genes. Nucleic Acids Res 2003, 31:1805-1812.

5. Roberts RJ, Vincze T, Posfai J, Macelis D: REBASE-a database for DNA restriction and modification: enzymes, genes and genomes. Nucleic Acids Res 2010, 38:D234-236.

6. Pingoud A, Fuxreiter M, Pingoud V, Wende W: Type II restriction endonucleases: structure and mechanism. Cell Mol Life Sci 2005, 62:685-707.

7. Szybalski W: Universal restriction endonucleases: designing novel cleavage specificities by combining adapter oligo-deoxynucleotide and enzyme moieties. Gene 1985, 40:169-173. 
8. Podhajska AJ, Kim SC, Szybalski W: Conferring new specificities on restriction enzymes: cleavage at any predetermined site by combining an adapter oligodeoxynucleotide and a class-IIS enzyme. Meth Enzymol 1992, 216(part G):303-309.

9. Kim SC, Skowron PM, Szybalski W: Structural requirements for the FoklDNA interaction and oligonucleotide-instructed cleavage. J Mol Biol 1996, 258:638-649.

10. Szybalski W: Universal restriction endonuclease. 1990, 1-14, U.S. Patent No. 4, 935, 357.

11. Szybalski W, Kim SC, Hasan N, Podhajska AJ: Class-IIS restriction enzymes a review. Gene 1991, 100:13-26.

12. Ward R, Hawkins N, O'Grady R, Sheehan C, O'Connor T, Impey H, et al: Restriction endonuclease-mediated selective polymerase chain reaction: a novel assay for the detection of K-ras mutations in clinical samples. Am J Pathol 1998, 153:373-379.

13. Morgan R, Xiao J-P, Xu S-Y: Characterization of an extremely thermostable restriction enzyme, PspGl, from a Pyrococcus strain and cloning of the PspGI restriction-modification system in Escherichia coli. Appl Environ Microbiol 1998, 64(10):3669-3673.

14. Żylicz-Stachula A, Żołnierkiewicz O, Jeżewska-Frackowiak J, Skowron PM: Chemically-induced affinity star restriction specificity: a novel TspGWI/ sinefungin endonuclease with theoretical 3-bp cleavage frequency. BioTechniques 2011, 50:397-406.

15. The Restriction Enzyme Database. [http://rebase.neb.com].

16. Vitkute J, Maneliene $Z$, Janulaitis A: Two new thermostable Type II restriction endonucleases from Thermus aquaticus: Tatl and Taul, which recognize the novel nucleotide sequences $5^{\prime}-\mathrm{W} \wedge \mathrm{GTACW}-3^{\prime}$ and $5^{\prime}$ GCSG^C-3' respectively. FEMS Microbiol Lett 2001, 204:253-257.

17. Sato S, Hutchison CA III, Harris Jl: A thermostable sequence-specific endonuclease from Thermus aquaticus. Proc Natl Acad Sci USA 1977, 74:542-546.

18. Barker D, Hoff M, Oliphant A, White R: A second type II restriction endonuclease from Thermus aquaticus with unusual sequence specificity. Nucleic Acids Res 1984, 12(14):5567-5581.

19. Xu S-Y, Hsieh P-C: Method for cloning and producing the Tfil restriction endonuclease in E. coli. US Patent Office 2000, US 6133008

20. Morgan RD, Roberts RJ: A Novel restriction endonucleases, DNA encoding these endonucleases and methods for identifying new endonucleases with the same or varied specificity. International Patent Office 2007, Patent WO 200797778.

21. Castel AL, Nakamori M, Thornton CA, Pearson CE: Identification of restriction endonucleases sensitive to 5-cytosine methylation at nonCpG sites, including expanded (CAG)n/(CTG)n repeats. Epigenetics 2011, 6:417-421

22. Skowron PM, Majewski J, Zylicz-Stachula A, Rutkowska SM, Jaworowska Harasimowicz-Slowinska Rl: A new Thermus sp. class-IIS enzyme subfamily: isolation of a 'twin' endonuclease TspDTI with a novel specificity 5'-ATGAA(N(11/9))-3', related to TspGWI, Taqll and Tth1111I. Nucleic Acids Res 2003, 31:e74

23. Zylicz-Stachula A, Harasimowicz-Slowinska Rl, Sobolewski I, Skowron PM: TspGWI, a thermophilic class-IIS restriction endonuclease from Thermus sp., recognizes novel asymmetric sequence 5'-ACGGA(N11/9)-3'. Nucleic Acids Res 2002, 30:e33.

24. Welch SG, Williams RAD: Two thermostable type II restriction endonucleases from Icelandic strains of the genus Thermus: Tsp4C I (ACN/GT), a novel type II restriction endonuclease, and Tsp8E I, an isoschizomer of the mesophilic enzyme Bgll (GCCNNNN/NGGC). Biochem J 1995, 309:595-599.

25. Raven NDH, Kelly CD, Carter ND, Eastlake P, Brown C, Williams RAD: A new restriction endonuclease, $\mathrm{TspEI}$, from the genus Thermus that generates cohesive termini compatible with those of EcoRl. Gene 1993, 131:83-86.

26. Raven NDH, Williams RAD, Smith KE, Kelly CD, Carter ND: Tsp45I, a new thermostable site-specific endonuclease that cleaves the recognition sequence 5'-GTSAC-3'. Nucleic Acids Res 1993, 21:4397.

27. Benner J, Dalton MA, Xu S, Dore A: A method for cloning and expression of TspRI restriction endonuclease and TspRI methylase in E. coli. Japanese Patent Office 2005, JP 200550684

28. Jurenaite-Urbanaviciene S: Engineering of bifunctional restriction endonucleases with novel specificities. PhD Thesis Vilnius University; 2008, $1-46$.
29. Shinomiya T, Sato S: A site specific endonuclease from Thermus thermophilus 111, Tth1111. Nucleic Acids Res 1980, 8:43-56.

30. Shinomiya T, Kobayashi M, Sato S: A second site specific endonuclease from Thermus thermophilus 111, Tth111I. Nucleic Acids Res 1980, 8:3275-3285.

31. Zylicz-Stachula A, Bujnicki JM, Skowron PM: Cloning and analysis of bifunctional DNA methyltransferase/nuclease TspGWI, the prototype of a Thermus sp. family. BMC Mol Biol 2009, 10:52.

32. Wei H, Therrien C, Blanchard A, Guan S, Zhu Z: The Fidelity Index provides a systematic quantitation of star activity of DNA restriction endonucleases. Nucleic Acids Res 2008, 36(9):e50.

33. Mead D, Swaminathan N, Van Etten J, Skowron PM: Recombinant CviJ restriction endonuclease. United States Patent Office 1995, no US005472872A, USA.

34. Swaminathan N, McMaster K, Skowron PM, Mead DA: Thermal Cycle Labeling: zeptomole detection sensitivity and microgram probe amplification using CviJl*restriction generated oligonucleotides. Anal. Biochem 1998, 255:133-141.

35. Sambrook J, Fitsch EF, Maniatis T: Molecular Cloning: A Laboratory Manual. 2 edition. Cold Spring Harbor NY: CSH Laboratory Press; 1989.

doi:10.1186/1471-2091-12-62

Cite this article as: Żylicz-Stachula et al:: Bifunctional Taqll restriction endonuclease: redefining the prototype DNA recognition site and establishing the Fidelity Index for partial cleaving. BMC Biochemistry 2011 12:62.

\section{Submit your next manuscript to BioMed Central and take full advantage of:}

- Convenient online submission

- Thorough peer review

- No space constraints or color figure charges

- Immediate publication on acceptance

- Inclusion in PubMed, CAS, Scopus and Google Scholar

- Research which is freely available for redistribution

Submit your manuscript at www.biomedcentral.com/submit
C) Biomed Central 